\title{
Paternal Adjustment and Paternal Attitudes Questionnaire: Antenatal and Postnatal Portuguese Versions
}

Assessment

$1-11$

(C) The Author(s) 2015

Reprints and permissions:

sagepub.com/journalsPermissions.nav DOI: $10.1177 / 1073191115621794$

asm.sagepub.com

\author{
Tiago Miguel Pinto', Catarina Samorinha ${ }^{2}$, Iva Tendais', Rui Nunes-Costa', \\ and Bárbara Figueiredo'
}

\begin{abstract}
The Paternal Adjustment and Paternal Attitudes Questionnaire (PAPA) was designed to assess paternal adjustment and paternal attitudes during the transition to parenthood. This study aimed to examine the psychometric characteristics of the Portuguese versions of the PAPA-Antenatal (PAPA-AN) and -Postnatal (PAPA-PN) versions. A nonclinical sample of 128 fathers was recruited in the obstetrics outpatient unit, and they completed both versions of the PAPA and selfreport measures of depressive and anxiety symptoms during pregnancy and the postpartum period, respectively. Good internal consistency for both PAPA-AN and PAPA-PN was found. A three-factor model was found for both versions of the instrument. Longitudinal confirmatory factor analysis revealed a good model fit. The PAPA-AN and PAPA-PN subscales revealed good internal consistency. Significant associations were found between PAPA (PAPA-AN and PAPA-PN) and depressive and anxiety symptoms, suggesting good criterion validity. Both versions also showed good clinical validity, with optimal cutoffs found. The present study suggested that the Portuguese versions of the PAPA are reliable multidimensional self-report measures of paternal adjustment and paternal attitudes that could be used to identify fathers with adjustment problems and negative attitudes during the transition to parenthood.
\end{abstract}

\section{Keywords}

Paternal Adjustment and Paternal Attitudes Questionnaire, psychometric characteristics, fathers, paternal adjustment, paternal attitudes, depressive and anxiety symptoms

The transition to parenthood is a major life event that leads both men and women to perform several developmental tasks in order to adapt to a wide range of biological, psychological, and sociocultural changes. A positive performance of these developmental tasks allows an adaptive transition to parenthood, leading to psychological adjustment and development and to preparing for adequate parenting. Contrarily, a negative performance of these developmental tasks may lead to an increase of psychopathological symptoms and inadequate parenting (e.g., C. P. Cowan \& Cowan, 2000; P. A. Cowan, 1991; Figueiredo, 2014).

Several studies have analyzed men's psychological adjustment during the transition to parenthood, suggesting that they are at risk for psychopathological symptoms (e.g., Figueiredo \& Conde, 2011; Matthey, Barnett, Ungerer, \& Waters, 2000; Parfitt \& Ayers, 2014). Studies have referred that men are particularly at risk for high anxiety symptoms during the first trimester of pregnancy, related with difficulties in performing early developmental tasks within the transition to parenthood (e.g., pregnancy acceptance; e.g., Boyce, Condon, Barton, \& Corkindale, 2007; Figueiredo \& Conde, 2011; Parfitt \& Ayers, 2014). Empirical studies found that more than $10.0 \%$ of men showed high anxiety during pregnancy (e.g., Figueiredo \& Conde, 2011; Parfitt $\&$ Ayers, 2014). The postpartum period was also reported as a period of vulnerability for men's depressive symptoms: $7.2 \%$ of men showed high depression at 3 months postpartum (Figueiredo \& Conde). The adjustment to parenting and to the new interactions within the family may also be particularly challenging for them (e.g., Edhborg, Matthiesen, Lundh, \& Widström, 2005; Figueiredo \& Conde, 2011; Matthey et al., 2000).

Higher levels of depressive and anxiety symptoms are strong indicators of men's psychological adjustment problems during the transition to parenthood. Other dimensions, beside depressive and anxiety symptoms, could as well be consistent indicators of men's psychological adjustment

\footnotetext{
'School of Psychology, University of Minho, Braga, Portugal

${ }^{2}$ University of Porto Medical School, Porto, Portugal

Corresponding Author:

Tiago Miguel Pinto, School of Psychology, University of Minho, Campus of Gualtar, 47 I0-057 Braga, Portugal.

Email: a57408@alunos.uminho.pt
} 
problems during the transition to parenthood. During pregnancy and the postpartum period, a man's psychological adjustment problems related to the transition to parenthood could be assessed through the way in which he views his sexual and marital relationship, and the pregnancy and the baby. Studies have showed that men's sexual desire, satisfaction, and activity decrease during the transition to parenthood (e.g., Condon, Boyce, \& Corkindale, 2004). A decrease in marital relationship quality during pregnancy and the postpartum period has also been found (e.g., Lawrence, Rothman, Cobb, Rothman, \& Bradbury, 2008; Mitnick, Heyman, \& Smith Slep, 2009). Additionally, studies have reported that marital relationship quality is negatively associated with men's depressive symptoms, and positively associated with men's involvement with pregnancy and father-infant interaction during the postpartum period (e.g., Feldman, 2000; Huang \& Warner, 2005).

Moreover, men with more positive attitudes toward pregnancy and the baby were found to be more involved with the pregnancy and the baby (e.g., Palkovitz \& Copes, 1988), whereas men with more negative attitudes toward pregnancy and the baby were found to interact poorly with their baby (e.g., Beitel \& Parke, 1998). Other studies have found that men with more negative attitudes toward the partner and the pregnancy display higher rates of depressive symptoms during the postpartum period (e.g., Leathers \& Kelley, 2000).

Paternal adjustment and paternal attitudes appear to be significant dimensions of men's psychological adjustment problems while transitioning to parenthood. Likewise, a measure of these dimensions may provide a multidimensional assessment of men's paternal adjustment problems during this transition.

To assess paternal adjustment and paternal attitudes, Marks, Wieck, Checkley, and Kumar (1992) have designed the Paternal Adjustment and Paternal Attitudes Questionnaire (PAPA) through an adaptation of the Maternal Adjustment and Maternal Attitudes Questionnaire (Kumar, Robson, \& Smith, 1984). The PAPA is a multidimensional self-report measure with an antenatal version (PAPA-AN) and a postnatal version (PAPA-PN), which allow the assessment of paternal adjustment and paternal attitudes during pregnancy and the postpartum period. Both versions of the PAPA comprise 30 items and include three subscales to assess men's sexual and marital relationship, and his paternal attitudes.

The PAPA-AN and the PAPA-PN may be valuable resources for clinical practitioners and researchers to assess relevant dimensions of men's psychological adjustment during the transition to parenthood. The assessment of these dimensions may be essential to better explore the processes involved on men's transition to parenthood. These dimensions could interact with other relevant variables during this period, acting as possible moderators and mediators of men's transition to parenthood. When compared with other measures that have been used to assess men's psychological adjustment problems during the transition to parenthood (e.g., the Edinburgh Postnatal Depression Scale [EPDS] and the State Anxiety Inventory [STAI-S]), both versions of the PAPA present advantages. The PAPA-AN and the PAPA-PN are self-report measures specifically designed to assess men's paternal adjustment and paternal attitudes. Moreover, as multidimensional measures, both versions of the PAPA allow the assessment of particular dimensions of men's psychological adjustment during the transition to parenthood - attitudes toward sex, the marital relationship, and attitudes toward pregnancy and the baby - that may be associated with psychopathological symptoms (e.g., depressive and anxiety symptoms) during this period.

Both versions of the PAPA have been used in some empirical studies (e.g., Lovestone \& Kumar, 1993; Marks et al., 1992). The PAPA-AN was used to analyze the effects of paternal adjustment and paternal attitudes during pregnancy on the psychological adjustment of the partner during the postpartum period (Marks et al., 1992). In another study, the effects of women's psychiatric illness on men's psychological adjustment were analyzed using the PAPA-PN (Lovestone \& Kumar, 1993). However, to our knowledge, the psychometric characteristics of both versions of the PAPA have not yet been reported.

The present study aimed to examine the psychometric characteristics of the Portuguese versions of the PAPA-AN and PAPA-PN. To examine the psychometric characteristics of the PAPA may represent an advance to the literature on the assessment of men's psychological adjustment during transition to parenthood. By examining the psychometric characteristics of both versions of the PAPA, the present study could help to clarify if these self-report measures are reliable to assess men's paternal adjustment and paternal attitudes during the transition to parenthood.

\section{Method}

\section{Participants}

The sample comprised 128 fathers who completed the antenatal and postnatal versions of the PAPA. Participants were recruited in two health services in Portugal. Inclusion criteria were read or write in Portuguese. From the 175 participants contacted, $166(94.9 \%)$ agreed to participate and signed a consent form, and 161 (92.0\%) completed the antenatal version of the PAPA. From the 161 participants that completed the antenatal version of the PAPA, 128 (79.5\%) completed both versions and were included in study analyses.

Nearly all the participants were Portuguese $(94.0 \%)$ and Caucasian (94.0\%), employed in manual (qualified or not qualified) professions (91.4\%), and married and cohabiting 
Table I. Fathers' Sociodemographic Characteristics.

\begin{tabular}{|c|c|}
\hline Characteristic & $\%$, Total $N=128$ \\
\hline \multicolumn{2}{|l|}{ Age (years) } \\
\hline $18-29$ & 26.6 \\
\hline $30-39$ & 67.9 \\
\hline $40-49$ & 5.5 \\
\hline \multicolumn{2}{|l|}{ Socioeconomic level } \\
\hline High & 17.4 \\
\hline Medium high & 12.4 \\
\hline Medium & 24.7 \\
\hline Medium-low & 30.6 \\
\hline Low & 14.9 \\
\hline \multicolumn{2}{|l|}{ Professional status } \\
\hline Employed & 91.4 \\
\hline Unemployed & 7.8 \\
\hline $\begin{array}{l}\text { Household or } \\
\text { student }\end{array}$ & 0.8 \\
\hline \multicolumn{2}{|l|}{ Education (in years) } \\
\hline$<9$ & 33.6 \\
\hline $9-12$ & 39.8 \\
\hline$>12$ & 26.6 \\
\hline \multicolumn{2}{|l|}{ Matrimonial status } \\
\hline Married & 74.2 \\
\hline Cohabitation & 18.0 \\
\hline Single & 7.8 \\
\hline \multicolumn{2}{|l|}{ Parity } \\
\hline Primiparous & 88.3 \\
\hline Multiparous & 11.7 \\
\hline \multicolumn{2}{|l|}{ Mode of conception } \\
\hline Spontaneous & 68.7 \\
\hline Medically assisted & 31.3 \\
\hline \multicolumn{2}{|l|}{ Pregnancy type } \\
\hline Singleton & 68.7 \\
\hline Twin & 31.3 \\
\hline
\end{tabular}

$(92.2 \%)$. More than a half of the participants were between 30 and 39 years old $(M=32.03, S D=4.87)$ and belonged to a medium-low and medium socioeconomic level (55.3\%). The majority of the participants were primiparous $(88.3 \%)$, had conceived spontaneously (68.7\%), and had a singleton pregnancy $(68.7 \%$; see Table 1$)$.

\section{Procedure}

The present research was conducted in accordance with the Helsinki Declaration and received previous approval from the University of Minho Ethical Commission as well as from the two medical institutions. Fathers were randomly recruited in the obstetrics outpatient unit after the first ultrasound of the fetus (8-14 gestational weeks), and the aims and the procedures were explained. Participants completed the PAPA-AN and the PAPA-PN during pregnancy $(M=$ 13.89 gestational weeks, $S D=2.23$ ) and the postpartum period $(M=24.59$ weeks postpartum, $S D=4.42)$, respectively. Fathers also completed self-report measures of depressive - the EPDS (Cox, Holden, \& Sagovsky, 1987) and anxiety symptoms - the State Anxiety Inventory (Spielberger, Gorsuch, Lushene, Vagg, \& Jacobs, 1983).

\section{Measures}

The PAPA. The PAPA-AN and the PAPA-PN (Marks et al., 1992) comprise 30 items scored on a 4-point Likert-type scale, ranging from 1 (never) to 4 (very often). PAPA-AN subscales are the following: (1) attitudes toward sex (e.g., Have you felt tense and unhappy at the thought of sexual intercourse?), (2) marital relationship (e.g., Have you felt that your partner was paying you too little attention?), and (3) attitudes toward pregnancy and baby (e.g., Have you regretted about your partner being pregnant?). Similarly, PAPA-PN subscales are the following: (1) attitudes toward sex (e.g., Do you think your partner has found you sexually desirable?), (2) marital relationship (e.g., Has your partner seemed to ignore how you were feeling?), and (3) attitudes toward baby (e.g., Have you felt that feeding your baby was pleasant?). Each subscale has 10 items. Higher scores on the PAPA-AN and the PAPA-PN indicate higher paternal adjustment and more positive paternal attitudes during pregnancy and the postpartum period, respectively. From the 30 items of the PAPA-AN, 15 items $(50.0 \%)$ are reverse scored. From the 30 items of the PAPA-PN, 14 items $(46.7 \%)$ are reverse scored. The items are reverse scored both for the total score and the subscales (see Tables 2 and $3)$.

The Portuguese versions of the PAPA are based on Portuguese spoken and written in Portugal. To compose the Portuguese versions, all PAPA-AN and PAPA-PN items were translated to Portuguese and back-translated to English. The translation was discussed by two bilingual researchers and a backward translation was performed by another bilingual researcher. The three researchers discussed the backward translation and consensus was reached through discussion.

PAPA Criterion Validity. Two measures of psychopathological symptoms (depressive and anxiety symptoms) were used to assess both PAPA-AN and PAPA-PN criterion validity.

The EPDS(Cox et al., 1987) was used to assess depressive symptoms during pregnancy and the postpartum period. The EPDS is a 10-item self-report scale scored on a 4-point Likert-type scale, designed to assess postpartum depression. This measure assesses the intensity of depressive symptoms within the previous 7 days and has been used in several studies with men during pregnancy and the postpartum period (e.g., Figueiredo \& Conde, 2011; Parfitt \& Ayers, 2014; Teixeira, Figueiredo, Conde, Pacheco, \& Costa, 2009). EPDS Portuguese version showed good internal consistency during pregnancy and the postpartum period $(\alpha=.85)$ and an optimal clinical cutoff of 10 to screen for 
Table 2. PAPA-AN Internal Consistency: Cronbach's alpha, Mean-Item Correlation, Item-Total Correlation, and Cronbach's Alpha if Item Deleted.

\begin{tabular}{|c|c|c|c|c|}
\hline Item & & MIC & ITC & $\alpha$ IID \\
\hline Attitu & es toward $\operatorname{sex}(\alpha=.82)$ & .581 & & \\
\hline 2. & Have you found your partner sexually desirable? & & .818 & .77 \\
\hline 6. & Do you think your partner has found you sexually desirable? & & .397 & .82 \\
\hline 10. & Have you felt shy about sex? R & & .737 & .78 \\
\hline II. & Have you felt that sexual intercourse might be less private because there is a baby inside of your partner? $R$ & & .790 & .77 \\
\hline 13. & Have you enjoyed kissing and petting? & & .380 & .82 \\
\hline 19. & Have you felt tense and unhappy at the thought of sexual intercourse? R & & .351 & .82 \\
\hline 22. & Have you felt that sex was unpleasant? R & & .756 & .78 \\
\hline 23. & Have you felt you were easily aroused sexually? & & .644 & .79 \\
\hline 25. & Have you been having pleasurable daydreams about sex? & & .370 & .82 \\
\hline 29. & Have you wanted to have sexual intercourse? & & .566 & .80 \\
\hline Marit: & relationship $(\alpha=.74)$ & .516 & & \\
\hline $\mathrm{I}$. & Has there been tension between you and your partner - irritability, unpleasant silence, etc.? R & & .353 & .74 \\
\hline 4. & Have arguments between you and your partner come close to blows? R & & .735 & .65 \\
\hline 8. & Have you found it easy to show affection to your partner? & & .312 & .74 \\
\hline 14. & Have you helped in the running of the house? & & .304 & .75 \\
\hline 16. & Have you felt that your partner was paying you too little attention? R & & .699 & .66 \\
\hline 18. & Has your partner seemed to ignore how you were feeling? R & & .607 & .68 \\
\hline 20. & Has your partner tried to share your interests? & & .721 & .66 \\
\hline 24. & Have you been feeling close to your partner since her became pregnant? & & .739 & .65 \\
\hline 26. & Has your partner shown affection to you? & & .387 & .74 \\
\hline 28. & Have you wished you could rely more on your partner to look after you? R & & .301 & .75 \\
\hline Attitu & es toward pregnancy and baby $(\alpha=.7 I)$ & .488 & & \\
\hline 3. & Have you been worrying that you might not be a good father? R & & .377 & .71 \\
\hline 5. & Have you been worrying about hurting your baby inside of your partner? R & & .339 & .71 \\
\hline 7. & Has it worried you that you may not have any time to yourself once your baby is born? R & & .371 & .71 \\
\hline 9. & Have you regretted about your partner being pregnant? R & & .317 & .72 \\
\hline 12. & Have you been feeling happy that your partner is pregnant? & & .756 & .58 \\
\hline 15. & Has the thought of having several children appealed to you? & & .394 & .70 \\
\hline 17. & Have you felt that pregnancy was unpleasant? R & & .632 & .62 \\
\hline 21. & Have you been looking forward to caring for your baby's needs? & & .728 & .60 \\
\hline 27. & Have you felt that life will be more difficult after the baby is born? R & & .334 & .71 \\
\hline 30. & Has the thought of take care of your baby appealed to you? & & .632 & .62 \\
\hline
\end{tabular}

Note. MIC = mean-item correlation; ITC = Item-total correlation; $\alpha=$ Cronbach's alpha; IID = if item deleted; $\mathrm{R}=$ reverse- score item. Paternal Adjustment and Paternal Attitudes Questionnaire-Antenatal version $(\alpha=.91)$.

depression in men during pregnancy and the postpartum period (e.g., Figueiredo \& Conde, 2011). In the present sample, Cronbach's alpha coefficient was .80 during pregnancy and .77 during the postpartum period.

The State-Trait Anxiety Inventory (STAI; Spielberger et al., 1983) is a self-report scale comprised by two subscales, the state anxiety and the trait anxiety, each containing 20 items scored on a 4-point Likert-type scale. The State Anxiety Inventory (STAI-S) that measures the temporary condition of "state anxiety" (anxiety in a specific situation) was used to assess anxiety symptoms during pregnancy and the postpartum period. Several studies have used this measure with men during pregnancy and the postpartum period (e.g., Figueiredo \& Conde, 2011; Figueiredo et al., 2008).
STAI-S Portuguese version showed good internal consistency ( $\alpha=.88$; Biaggio, Natalicio, \& Spielberger, 1976). In the present sample, Cronbach's alpha coefficient was .88 during pregnancy and .92 during the postpartum period.

\section{Analytical Strategy}

To examine the psychometric characteristics of the PAPA-AN and the PAPA-PN, analyses of (1) internal consistency, (2) factor structure, (3) criterion validity and (4) clinical validity were performed. To examine (1) PAPA-AN and PAPA-PN (total scale and subscales) internal consistency, analyses of Cronbach's alpha coefficient, item-total correlation, and mean-item correlation were performed. 
Table 3. PAPA-PN Internal Consistency: Cronbach's Alpha, Mean-Item Correlation, Item-Total Correlation, and Cronbach's Alpha if Item Deleted.

\begin{tabular}{|c|c|c|c|c|}
\hline \multicolumn{2}{|l|}{ Item } & MIC & ITC & $\alpha \operatorname{IID}$ \\
\hline \multicolumn{2}{|c|}{ Attitudes toward sex $(\alpha=.8 \mathrm{I})$} & .492 & & \\
\hline 2. & Have you found your partner sexually desirable? & & .820 & .74 \\
\hline 6. & Do you think your partner has found you sexually desirable? & & .314 & .81 \\
\hline 10. & Have you felt shy about sex? R & & .744 & .75 \\
\hline II. & Have you felt that sexual intercourse is less private now you have a baby? $R$ & & .612 & .77 \\
\hline 13. & Have you enjoyed kissing and petting? & & .399 & .80 \\
\hline 19. & Have you felt tense and unhappy at the thought of sexual intercourse? R & & .312 & .81 \\
\hline 22. & Have you felt that sex was unpleasant? R & & .380 & .80 \\
\hline 23. & Have you felt you were easily aroused sexually? & & .650 & .77 \\
\hline 25. & Have you been having pleasurable daydreams about sex? & & .373 & .81 \\
\hline 29. & Have you wanted to have sexual intercourse? & & .317 & .81 \\
\hline \multicolumn{2}{|c|}{ Marital relationship $(\alpha=.87)$} & .614 & & \\
\hline $\mathrm{I}$. & Has there been tension between you and your partner - irritability, unpleasant silence, etc.? R & & .481 & .86 \\
\hline 4. & Have arguments between you and your partner come close to blows? R & & .804 & .84 \\
\hline 8. & Have you found it easy to show affection to your partner? & & .396 & .87 \\
\hline 14. & Have you helped in the running of the house? & & .302 & .88 \\
\hline 16. & Have you felt that your partner was paying you too little attention? R & & .863 & .83 \\
\hline 18. & Has your partner seemed to ignore how you were feeling? R & & .845 & .83 \\
\hline 20. & Has your partner tried to share your interests? & & .813 & .84 \\
\hline 24. & Have you been feeling close to your partner since your baby was born? & & .439 & .87 \\
\hline 26. & Has your partner shown affection to you? & & .786 & .84 \\
\hline 28. & Have you wished you could rely more on your partner to look after you? R & & .414 & .87 \\
\hline \multicolumn{2}{|r|}{ Attitudes toward pregnancy and baby $(\alpha=.74)$} & .515 & & \\
\hline 3. & Have you been worrying that you might not be a good father? R & & .441 & .73 \\
\hline 5. & Have you been worrying about hurting your baby? R & & .403 & .73 \\
\hline 7. & Have you felt that you have time to yourself since your baby was born? & & .391 & .74 \\
\hline 9. & Have you regretted about have your baby? $\mathrm{R}$ & & .393 & .74 \\
\hline 12. & Have you been feeling happy about have your baby? & & .553 & .71 \\
\hline 15. & Has the thought of having several children appealed to you? & & .499 & .73 \\
\hline 17. & Have you felt disappointed about being a father? $\mathrm{R}$ & & .651 & 69 \\
\hline 21. & Have you felt that care for your baby's needs was pleasant? & & .607 & .70 \\
\hline 27. & Have you felt that life is more difficult after the baby was born? R & & .669 & 69 \\
\hline 30. & Have you felt that feeding your baby was pleasant? & & .542 & .71 \\
\hline
\end{tabular}

Note. MIC = mean-item correlation; ITC = item-total correlation; $\alpha=$ Cronbach's alpha; IID = if item deleted; $\mathrm{R}=$ reverse-scored item. Paternal Adjustment and Paternal Attitudes Questionnaire-Postnatal version $(\alpha=.90)$.

According to Field (2005), good internal consistency is indicated when Cronbach's alpha coefficient is higher than .70 , the item-total correlation is over .30, and the meanitem correlation is higher than .15. To examine (2) PAPA-AN and PAPA-PN factor structure, a longitudinal confirmatory factor analysis (maximum likelihood estimation) was performed. Following recommendations (e.g., Kline, 2005), indices from different classes were computed to analyze model goodness of fit: the chi-square statistic, the comparative fit index (CFI), and the root mean square error of approximation (RMSEA). Kline (2005) recommends that a good model fit is evidenced by a nonsignificant chi-square, a CFI of at least .95 , and an RMSEA of .05 or less. Pearson correlations were performed to analyze PAPA-AN and
PAPA-PN intercorrelations. To examine (3) PAPA-AN and PAPA-PN criterion validity, Pearson correlations with the PAPA-AN and the PAPA-PN (total scale and subscales) and depressive and anxiety symptoms were performed. The threshold of statistical significance was corrected using Benjamini-Hochberg's method (Benjamini \& Hochberg, $1995)$ to control the false positive rate of all Pearson correlations. To examine (4) PAPA-AN and PAPA-PN clinical validity, receiver operating curve (ROC) analyses were performed. PAPA-AN and PAPA-PN screening performance to identify fathers without adjustment problems (EPDS $<10)$ and fathers with adjustment problems (EPDS $\geq 10$ ) was analyzed. The area under the curve (AUC) provides an estimate of the overall diagnostic ability of the instrument 
(higher values indicating greater classification accuracy). The AUC of .70 is considered acceptable, .80 as excellent and .90 as outstanding (e.g., Hosmer \& Lemeshow, 2000). Sensitivity, specificity, positive predictive values and negative predictive values for the PAPA-AN and PAPA-PN cutoff scores were computed. According to Bland (200), the optimal cutoff scores were determined by identifying the closest value to the intersection of the ROC curve with the diagonal line from the upper left to the lower right side of the graph.

Statistical analyses were performed using SPSS and SPSS Amos Version 22.0.

\section{Results}

\section{PAPA-AN and PAPA-PN Internal Consistency}

Cronbach's alphas for the PAPA-AN and the PAPA-PN (total scale and subscales) were computed. Values over .70 were observed in both versions $(\alpha=.91$ for PAPA-AN and $\alpha=.90$ for PAPA-PN). All PAPA-AN subscales also presented Cronbach's alpha higher than .70: attitudes toward sex $(\alpha=.82)$, marital relationship $(\alpha=.74)$, and attitudes toward pregnancy and baby $(\alpha=.71)$. Additionally, values over .70 were also found for all PAPA-PN subscales: attitudes toward sex $(\alpha=.81)$, marital relationship $(\alpha=.87)$, and attitudes toward baby $(\alpha=.74)$.

Moreover, all PAPA-AN and PAPA-PN items presented an item-total correlation higher than .30, and mean-item correlations higher than .15 were found for all the subscales (see Tables 2 and 3).

\section{PAPA-AN and PAPA-PN Factor Structure}

Longitudinal confirmatory factor analysis revealed a good model fit, $\chi^{2}(6)=10.28, p=.168, \mathrm{RMSEA}=.04, \mathrm{CFI}=.99$. The PAPA-AN and the PAPA-PN subscales showed high loadings on both PAPA-AN and PAPA-PN latent factors, respectively. The lowest factor loading was for attitudes toward baby and pregnancy on the PAPA-AN latent factor (.88) and for attitudes toward baby on the PAPA-PN latent factor (.73). Moreover, the model indicated that higher scores on the PAPA-AN latent factor predicted higher scores on the PAPA-PN latent factor, $\beta=.87, p<.001$ (see Figure 1).

\section{PAPA-AN and PAPA-PN Intercorrelations}

Pearson correlations revealed that the three PAPA-AN subscales were positively correlated with the PAPA-AN: attitudes toward sex with the PAPA-AN, $r=.920, p=.01$; marital relationship with the PAPA-AN, $r=.933, p=.01$; and attitudes toward pregnancy and baby with the PAPA-AN, $r=.906, p=.01$. Likewise, the PAPA-AN subscales were positively correlated: attitudes toward sex with marital relationship, $r=.781, p=.01$; attitudes toward sex with attitudes toward pregnancy and baby, $r=.733, p=.01$; and marital relationship with attitudes toward pregnancy and baby, $r=.795, p=.01$.

Pearson correlations also revealed that the three PAPA-PN subscales were positively correlated with the PAPA-PN: attitudes toward sex with the PAPA-PN, $r=$ $.879, p=.01$; marital relationship with the PAPA-PN, $r=$ $.936, p=.01$; and attitudes toward baby with the PAPA-PN, $r=.793, p=.01$. Likewise, the PAPA-PN subscales were positively correlated: attitudes toward sex with marital relationship, $r=.722, p=.01$; attitudes toward sex with attitudes toward baby, $r=.548, p=.01$; and marital relationship with attitudes toward baby, $r=.622, p=.01$ (see Table 4 ).

\section{PAPA-AN and PAPA-PN Criterion Validity}

Pearson correlations revealed significant negative correlations between the PAPA-AN (total scale and subscales) and depressive symptoms during pregnancy: the PAPA-AN with depressive symptoms, $r=-.484, p=.01$, attitudes toward sex with depressive symptoms, $r=-.395, p=.01$, marital relationship with depressive symptoms, $r=-.481$, $p=.01$, and attitudes toward pregnancy and baby with depressive symptoms, $r=-.464, p=.01$. Negative correlations between the PAPA-AN (total scale and subscales) and anxiety symptoms during pregnancy were found: the PAPA-AN with anxiety symptoms, $r=-.304, p=.01$, attitudes toward sex with anxiety symptoms, $r=-.278, p=.01$, marital relationship with anxiety symptoms, $r=-.277, p=$ .01 , and attitudes toward pregnancy and baby with anxiety symptoms, $r=-.284, p=.01$.

Pearson correlations also revealed significant negative correlations between the PAPA-PN (total scale and subscales) and depressive symptoms during the postpartum period: the PAPA-PN with depressive symptoms, $r=-.405$, $p=.01$, attitudes toward sex with depressive symptoms, $r=$ $-.273, p=.01$, marital relationship with depressive symptoms, $r=-.383, p=.01$, and attitudes toward baby with depressive symptoms, $r=-.438, p=.01$. Negative correlations between the PAPA-PN (total scale and subscales) and anxiety symptoms during the postpartum period were found: the PAPA-PN with anxiety symptoms, $r=-.292, p=$ .01 , attitudes toward sex with anxiety symptoms, $r=-.211$, $p=.01$, marital relationship with anxiety symptoms, $r=$ $-.235, p=.01$, and attitudes toward baby with anxiety symptoms, $r=-.371, p=.01$ (see Table 5).

\section{PAPA-AN and PAPA-PN Clinical Validity}

The AUC for the total score of the PAPA-AN was .81, 95\% confidence interval $[.71, .91], p<.001$. The optimal balance between sensitivity and specificity was achieved at a cutoff $\geq 95$ (sensitivity $=74.1 \%$ and specificity $=73.3 \%$ ). 


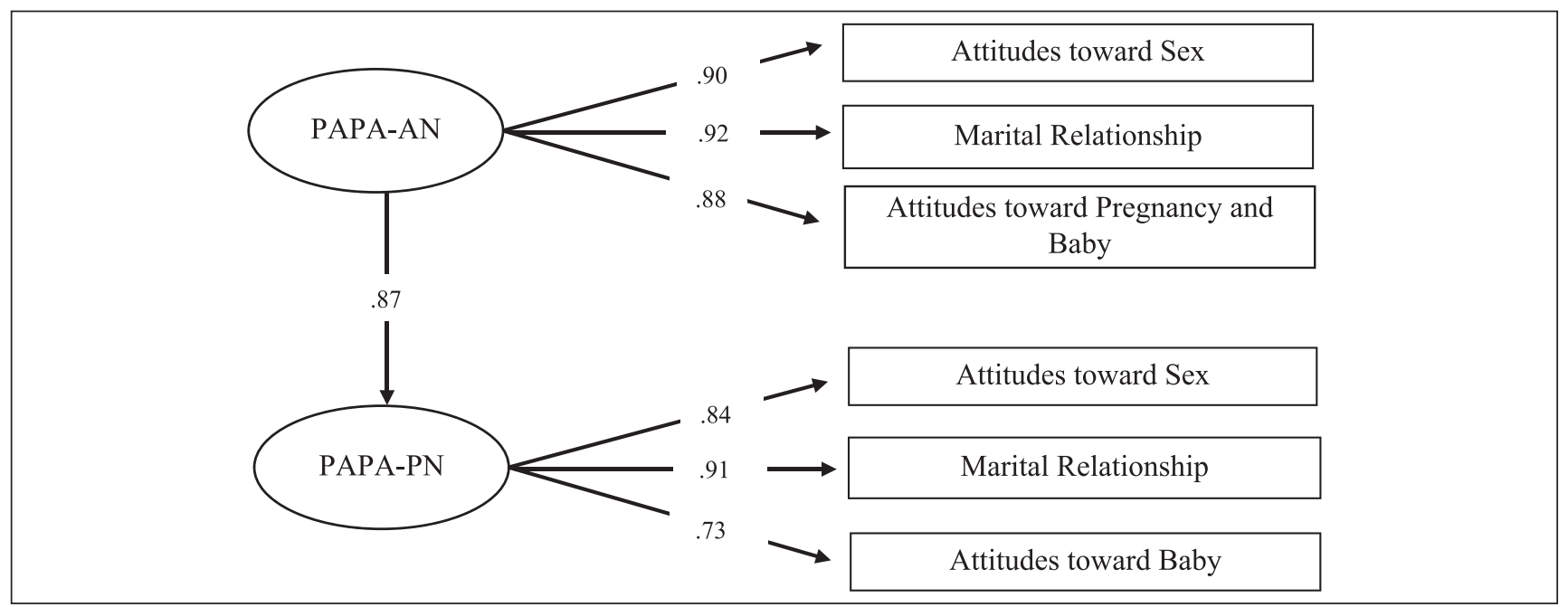

Figure I. Longitudinal confirmatory factor analysis of the Paternal Adjustment and Paternal Attitudes Questionnaire-Antenatal and -Postnatal versions (PAPA-AN, PAPA-PN).

Table 4. PAPA-AN and PAPA-PN Intercorrelations.

\begin{tabular}{|c|c|c|c|c|}
\hline & $\begin{array}{l}\text { PAPA- } \\
\text { AN }\end{array}$ & $\begin{array}{c}\text { AS (PAPA- } \\
\text { AN) }\end{array}$ & $\begin{array}{c}\text { MR } \\
\text { (PAPA-AN) }\end{array}$ & $\begin{array}{c}\text { APB } \\
\text { (PAPA-AN) }\end{array}$ \\
\hline PAPA-AN & 1.00 & & & \\
\hline AS (PAPA-AN) & $.920 *$ & 1.00 & & \\
\hline MR (PAPA-AN) & $.933 *$ & $.781 *$ & 1.00 & \\
\hline \multirow[t]{2}{*}{ APB (PAPA-AN) } & $.906 *$ & $.733^{*}$ & $.795^{*}$ & 1.00 \\
\hline & $\begin{array}{l}\text { PAPA- } \\
\text { PN }\end{array}$ & $\begin{array}{l}\text { AS (PAPA- } \\
\text { PN) }\end{array}$ & $\begin{array}{c}\text { MR } \\
\text { (PAPA-PN) }\end{array}$ & $\begin{array}{c}\text { AB } \\
\text { (PAPA-PN) }\end{array}$ \\
\hline PAPA-PN & 1.00 & & & \\
\hline AS (PAPA-PN) & $.879 *$ & 1.00 & & \\
\hline MR (PAPA-PN) & $.936 *$ & $.722 *$ & 1.00 & \\
\hline AB (PAPA-PN) & $.793 *$ & $.548 *$ & $.662 *$ & 1.00 \\
\hline
\end{tabular}

Note. PAPA-AN $=$ Paternal Adjustment and Paternal Attitudes Questionnaire-Antenatal version; AS (PAPA-AN) = attitudes toward sex (PAPA-AN subscale); MR (PAPA-AN) = marital relationship (PAPA-AN subscale); APB (PAPA-AN) = attitudes toward pregnancy and baby (PAPAAN subscale); PAPA-PN = Paternal Adjustment and Paternal Attitudes Questionnaire-Postnatal version; AS (PAPA-PN) = attitudes toward sex (PAPA-PN subscale); MR (PAPA-PN) = marital relationship (PAPA-PN subscale); $A B(P A P A-P N)=$ attitudes toward baby (PAPA-PN subscale). $*_{p}<.05$.

At this cutoff, $73.7 \%$ of fathers were correctly identified as fathers with and without adjustment problems during pregnancy.

For the total score of the PAPA-PN, the AUC was .80, $95 \%$ confidence interval $[.67, .92], p<.001$. A cutoff score of $\geq 92$ was the most appropriate (sensitivity $=75.0 \%$ and specificity $=73.3 \%$ ). At this cutoff, $74.2 \%$ of fathers were correctly identified as fathers with and without adjustment problems during the postpartum period (see Table 6 and Figure 2).
Table 5. PAPA-AN and PAPA-PN Criterion Validity: Correlations With Depressive and Anxious Symptoms During Pregnancy and the Postpartum Period, Respectively.

\begin{tabular}{lcccc}
\hline & PAPA- & AS (PAPA- & MR (PAPA- & APB (PAPA- \\
Pregnancy & AN & AN) & AN) & AN) \\
\hline $\begin{array}{c}\text { Depressive } \\
\text { symptoms }\end{array}$ & $-.484^{*}$ & $-.395^{*}$ & $-.48 I^{*}$ & $-.464^{*}$ \\
$\begin{array}{c}\text { Anxiety } \\
\text { symptoms }\end{array}$ & $-.304^{*}$ & $-.278^{*}$ & $-.277^{*}$ & $-.284^{*}$ \\
\hline Postpartum & PAPA- & AS (PAPA- & MR (PAPA- & AB (PAPA- \\
& PN & PN) & PN) & PN) \\
\hline $\begin{array}{c}\text { Depressive } \\
\text { symptoms }\end{array}$ & $-.405^{*}$ & $-.273^{*}$ & $-.383^{*}$ & $-.438^{*}$ \\
$\begin{array}{c}\text { Anxiety } \\
\text { symptoms }\end{array}$ & $-.292^{*}$ & $-.21 I^{*}$ & $-.235^{*}$ & $-.37 I^{*}$ \\
\hline
\end{tabular}

Note. PAPA-AN = Paternal Adjustment and Paternal Attitudes Questionnaire-Antenatal version; AS (PAPA-AN) = attitudes toward sex (PAPA-AN subscale); MR (PAPA-AN) = marital relationship $($ PAPA-AN subscale); APB (PAPA-AN) = attitudes toward pregnancy and baby (PAPAAN subscale); PAPA-PN = Paternal Adjustment and Paternal Attitudes Questionnaire-Postnatal version; AS (PAPA-PN) = attitudes toward sex (PAPA-PN subscale); MR (PAPA-PN) = marital relationship (PAPA-PN subscale); $A B($ PAPA-PN) = attitudes toward baby (PAPA-PN subscale). $*_{p}<.05$.

\section{Discussion}

The present study suggested the Portuguese version of the PAPA-AN and PAPA-PN as reliable multidimensional selfreport measures of paternal adjustment and paternal attitudes during pregnancy and the postpartum period. Both versions of the PAPA showed good internal consistency: (1) Cronbach's alpha higher than $.70(\alpha=.91$ for the PAPA-AN and $\alpha=.90$ for the PAPA-PN), (2) a mean-item correlation 
Table 6. PAPA-AN and PAPA-PN Screening Performance to Detect Fathers Without Adjustment Problems (EPDS < 10) and Fathers With Adjustment Problems (EPDS $\geq 10$ ) During Pregnancy and the Postpartum Period, Respectively (\%).

\begin{tabular}{cccccc}
\hline Threshold & Sensitivity & Specificity & PPV & NPV & Accuracy \\
\hline PAPA-AN $^{\mathrm{a}}$ & & & & & \\
89 & 81.3 & 60.0 & 93.4 & 31.4 & 70.7 \\
90 & 76.8 & 60.0 & 93.1 & 27.0 & 68.4 \\
92 & 76.8 & 66.7 & 94.2 & 29.1 & 71.8 \\
94 & 75.0 & 66.7 & 94.0 & 27.6 & 70.9 \\
95 & $\mathbf{7 4 . 1}$ & $\mathbf{7 3 . 3}$ & $\mathbf{9 5 . 1}$ & $\mathbf{2 8 . 8}$ & $\mathbf{7 3 . 7}$ \\
96 & 73.2 & 73.3 & 95.0 & 28.1 & 73.3 \\
97 & 69.6 & 73.3 & 94.8 & 25.6 & 71.5 \\
98 & 68.8 & 73.3 & 94.7 & 25.1 & 71.1 \\
99 & 65.2 & 73.3 & 94.5 & 23.1 & 69.3 \\
100 & 60.7 & 73.3 & 94.1 & 21.0 & 67.0 \\
PAPA-PN & & & & & \\
87 & 82.1 & 73.3 & 96.2 & 33.5 & 77.7 \\
88 & 80.4 & 73.3 & 96.1 & 31.5 & 76.9 \\
90 & 77.7 & 73.3 & 96.0 & 28.8 & 75.5 \\
91 & 75.9 & 73.3 & 95.9 & 27.2 & 74.6 \\
92 & $\mathbf{7 5 . 0}$ & $\mathbf{7 3 . 3}$ & $\mathbf{9 5 . 8}$ & $\mathbf{2 6 . 5}$ & $\mathbf{7 4 . 2}$ \\
94 & 70.5 & 73.3 & 95.6 & 23.4 & 71.9 \\
95 & 67.0 & 73.3 & 95.3 & 21.4 & 70.2 \\
96 & 65.2 & 73.3 & 95.2 & 20.6 & 69.3 \\
97 & 61.6 & 86.7 & 97.4 & 21.7 & 74.2 \\
98 & 58.0 & 86.7 & 97.3 & 20.2 & 72.4 \\
\hline
\end{tabular}

Note. PAPA-AN $=$ Paternal Adjustment and Paternal Attitudes Questionnaire-Antenatal version; PAPA-PN = Paternal Adjustment and Paternal Attitudes Questionnaire-Postnatal version; EPDS = Edinburgh Postnatal Depression Scale; PPV = positive predictive value; $\mathrm{NPV}=$ negative predictive value. Values in boldface represent the most adequate balance between sensitivity and specificity.

a Fathers without adjustment problems $(n=|| 2)$ and fathers with adjustment problems $(n=16)$ during pregnancy. ${ }^{b}$ Fathers without adjustment problems $(n=1 \mid 4)$ and fathers with adjustment problems $(n=14)$ during the postpartum period.

higher than .15, and (3) an item-total correlation higher than .30. The PAPA-AN and the PAPA-PN subscales also presented good internal consistency (Cronbach's alphas = .71-.87).

As suggested by Marks et al. (1992), a three-factor model was found for both versions of the PAPA. Longitudinal confirmatory factor analysis revealed a good model fit, indicating that the model replicate the covariance matrix. Moreover, longitudinal confirmatory factor analysis suggested that higher scores on the PAPA-AN predicted higher scores on the PAPA-PN.

Both versions of the PAPA revealed good criterion validity, showing negative associations with measures of psychopathological symptoms (depressive and anxiety symptoms) that have been used to measure men's psychological adjustment during the transition to parenthood (e.g., Figueiredo \& Conde, 2011; Matthey et al., 2000; Parfitt \&
Ayers, 2014). The PAPA-AN and the PAPA-PN (total score and subscales) showed negative associations with measures of depressive and anxiety symptoms during pregnancy and the postpartum period, respectively.

The results of clinical validity suggested good values for both versions of the PAPA - excellent classification accuracy power was found for both versions (e.g., Hosmer \& Lemeshow, 2000). The PAPA-AN and the PAPA-PN demonstrated high screening ability to identify fathers with and without adjustment problems and negative attitudes during pregnancy and the postpartum period, respectively. Optimal clinical cutoff scores for the PAPA-AN (95) and the PAPA-PN (92) were found (e.g., Bland, 2000). At these cutoffs, acceptable values of sensitivity and specificity and high positive predictive values were found. However, lower negative predictive values were found for both versions. Negative predictive values might be influenced by the low sample size of men with EPDS equal to or higher than 10 during pregnancy and the postpartum period, respectively. Nevertheless, the sample size of men with EPDS equal to or higher than 10 was similar to the sample size reported by previous studies with Portuguese men during the transition to parenthood (e.g., Areias, Kumar, Barros, \& Figueiredo, 1996; Figueiredo \& Conde, 2011). To our knowledge, this was the first study that provided optimal clinical cutoff scores for the PAPA-AN and the PAPA-PN.

\section{Limitations}

Some methodological limitations can be pointed out in this study. The voluntary nature of the participation may have led to a selection bias, in the sense that those who agreed to participate may in fact be those who feel more involved and satisfied with the pregnancy and the postpartum experience. Criterion and clinical validity analysis of the PAPA-AN and the PAPA-PN were performed only with screening selfreport measures (EPDS and STAI-S) with no diagnostic clinical examination used as a gold standard.

\section{Implications for Practice and Research}

The Portuguese version of the PAPA-AN and the PAPA-PN may be reliable self-report measures to assess paternal adjustment and paternal attitudes and may allow clinical practitioners to screen fathers with adjustment problems and negative attitudes during the transition to parenthood.

When compared with EPDS and STAI-S, the PAPA-AN and the PAPA-PN present advantages for clinical practice and research during the transition to parenthood. First, both versions of the PAPA are measures specifically designed to assess men's paternal adjustment and paternal attitudes. The PAPA-AN and the PAPA-PN also allow clinical practitioners and researchers to identify particular dimensions of men's psychological adjustment that reveal adjustment 


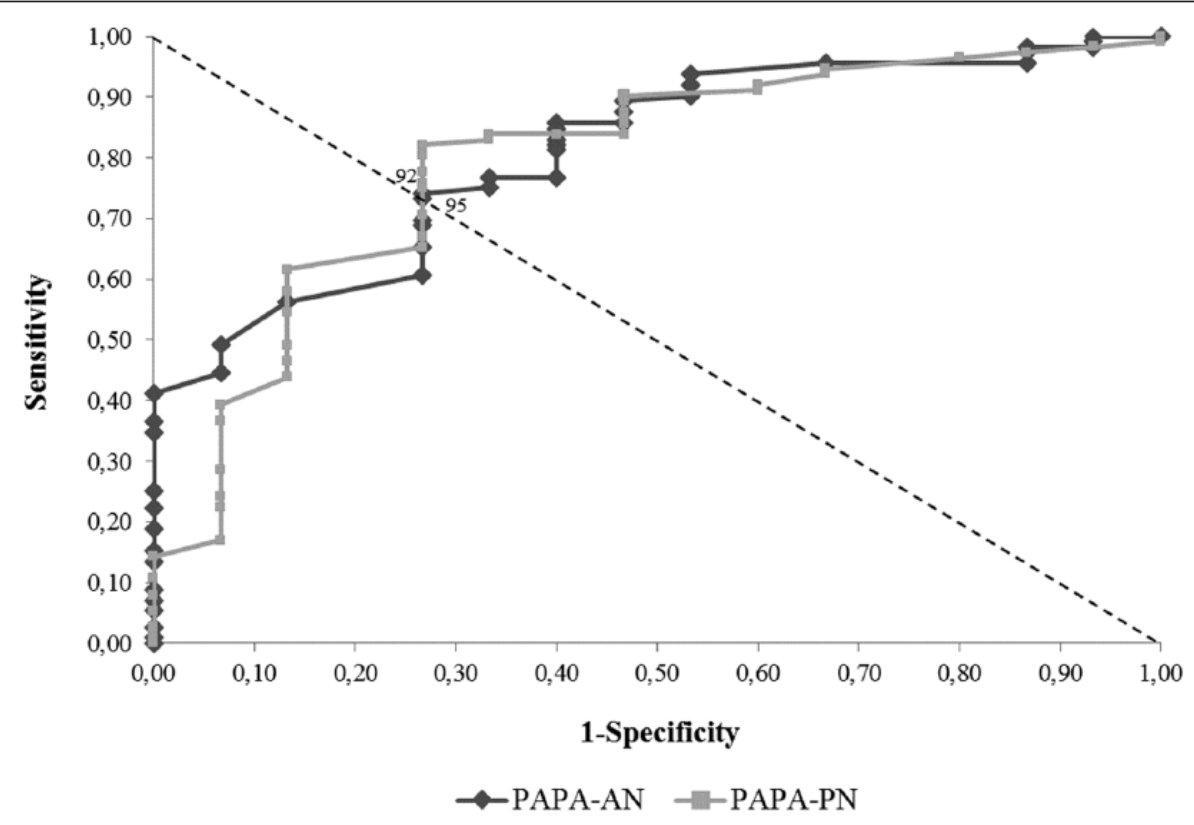

Figure 2. ROC curve for fathers without adjustment problems (EPDS < I0) versus fathers with adjustment problems (EPDS $\geq 10$ ): PAPA-AN $(n=112$ vs. $n=16)$, PAPA-PN ( $n=114$ vs. $n=14)$.

Note. ROC = receiver operating curve; EPDS = Edinburgh Postnatal Depression Scale; PAPA-AN = Paternal Adjustment and Paternal Attitudes Questionnaire-Antenatal version; PAPA-PN = Paternal Adjustment and Paternal Attitudes Questionnaire-Postnatal version.

problems - attitudes toward sex, the marital relationship, and attitudes toward pregnancy and the baby_ and may justify the presence of psychopathological symptoms.

Both versions of the PAPA showed good clinical validity. For clinical practitioners, screening for paternal adjustment problems and negative attitudes using the PAPA-AN during pregnancy as part of routine prenatal care appointments may provide an easy and valid strategy to identify fathers with adjustment problems and negative attitudes, and to provide information on dimensions that could benefit from psychological counseling. Simultaneously, the PAPA-AN may help identify during pregnancy fathers who may be at risk of adjustment problems during the postpartum period. Screening for paternal adjustment problems and negative attitudes using the PAPA-PN during the postpartum period as part of routine postnatal care appointments might also help clinical practitioners identify fathers with adjustment problems and negative attitudes, and intervene on the dimensions that reveal adjustment problems (e.g., marital relationship) during this period.

For researchers, both versions of the PAPA may be useful measures in studies on paternal adjustment and attitudes during pregnancy and the postpartum period. Following a developmental framework (C. P. Cowan \& Cowan, 2000), the PAPA-AN and the PAPA-PN may be valuable tools to explore men's developmental tasks within the transition to parenthood (e.g., the involvement with pregnancy and the baby) and contextual variables (e.g., marital relationship) that may interfere on the performance of these developmental tasks. To analyze paternal adjustment during the transition to parenthood, the processes involved, and its effects on parenting and infant developmental outcomes may provide important knowledge on fathers' experience during the transition to parenthood.

The PAPA might also allow the development of new designs for clinical interventions with men during the transition to parenthood. This new interventions could be specifically designed to intervene on the particular adjustment problems and negative attitudes experienced by men during pregnancy and the postpartum period.

The present study assessed some psychometric properties of the PAPA in a community sample of men during the transition to parenthood. Future studies might assess other psychometric properties of both versions of the PAPA, namely, test-retest reliability and concurrent validity. Additionally, studies might also examine the psychometric properties of the PAPA-AN and PAPA-PN in clinical samples of men comparing with diagnostic clinical interviews.

\section{Conclusion}

The present study suggested that the Portuguese versions of the PAPA are reliable multidimensional self-report measures of paternal adjustment and paternal attitudes that could be used to identify fathers with adjustment problems and negative attitudes during the transition to parenthood. 


\section{Authors' Note}

In the memory of Channi Kumar and Maureen Marks.

\section{Declaration of Conflicting Interests}

The author(s) declared no potential conflicts of interest with respect to the research, authorship, and/or publication of this article.

\section{Funding}

The author(s) disclosed receipt of the following financial support for the research, authorship, and/or publication of this article: This research was supported by FEDER Funds through the Programa Operacional Factores de Competitividade-COMPETE and by National Funds through FCT-Fundação para a Ciência e a Tecnologia under the project PTDC/SAU/SAP/116738/2010. This research was also supported by FEDER funding from the Operational Programme Factors of Competitiveness-COMPETE and by national funding from the FCT-Foundation for Science and Technology (Portuguese Ministry of Education and Science) within the project "Health, Governance and Accountability in Embryo Research: Couples' Decisions About the Fates of Embryos" (FCOMP-01-0124-FEDER-014453), and a PhD grant (SFRH/BD/75807/2011), cofunded by the POPH (Programa Operacional de Potencial Humano) Programme.

\section{References}

Areias, M. E., Kumar, R., Barros, H., \& Figueiredo, E. (1996). Comparative incidence of depression in women and men, during pregnancy and after childbirth: Validation of the Edinburgh Postnatal Depression Scale in Portuguese mothers. British Journal of Psychiatry, 169, 30-35. doi:10.1192/ bjp.169.1.30

Beitel, A. H., \& Parke, R. D. (1998). Paternal involvement in infancy: The role of maternal and paternal attitudes. Journal of Family Psychology, 12, 268-288. doi:10.1037/08933200.12.2.268

Benjamini, Y., \& Hochberg, Y. (1995). Controlling the false discovery rate: A practical and powerful approach to multiple testing. Journal of the Royal Statistical Society, 57, 289-300. Retrieved from http://www.jstor.org/stable/2346101

Biaggio, A. M., Natalicio, L., \& Spielberger, C. D. (1976). The development and validation of an experimental Portuguese form of the State-Trait Anxiety Inventory. In C. D. Spielberger \& R. Dias-Guerrero (Eds.), Cross-cultural research on anxiety (pp. 29-40). Washington, DC: Hemisphere.

Bland, M. (2000). An introduction to medical statistics (3rd ed.). Oxford, England: Oxford University Press.

Boyce, P., Condon, J., Barton, J., \& Corkindale, C. (2007). FirstTime Fathers' Study: Psychological distress in expectant fathers during pregnancy. Australian \& New Zealand Journal of Psychiatry, 41, 718-725. doi:10.1080/00048670701517959

Condon, J. T., Boyce, P., \& Corkindale, C. J. (2004). The FirstTime Fathers Study: A prospective study of the mental health and wellbeing of men during the transition to parenthood. Australian \& New Zealand Journal of Psychiatry, 38, 56-64. doi:10.1111/j.1440-1614.2004.01298.x

Cowan, C. P., \& Cowan, P. A. (2000). When partners become parents: The big life change for couples. Mahwah, NJ: Lawrence Erlbaum.
Cowan, P. A. (1991). Individual and family life transitions: A proposal for a new definition. In P. A. Cowan \& M. Hetherington (Eds.), Family transitions (pp. 3-26). Hillsdale, NJ: Erlbaum.

Cox, J. L., Holden, J. M., \& Sagovsky, R. (1987). Detection of postnatal depression: Development of the 10-item Edinburgh Postnatal Depression Scale. British Journal of Psychiatry, 150, 782-786. doi:10.1192/bjp.150.6.782

Edhborg, M., Matthiesen, A. S., Lundh, W., \& Widström, A. M. (2005). Some early indicators for depressive symptoms and bonding 2 months postpartum: A study of new mothers and fathers. Archives of Women's Mental Health, 8, 221-231. doi:10.1007/s00737-005-0097-5

Feldman, R. (2000). Parents' convergence on sharing and marital satisfaction, father involvement, and parent-child relationship at the transition to parenthood. Infant Mental Health Journal, 21, 176-191. doi:10.1002/10970355(200007)21:3<176::AID$\mathrm{IMHJ} 3>3.0 . \mathrm{CO} ; 2-4$

Field, A. (2005). Discovering Statistics using SPSS. London, England: Sage.

Figueiredo, B. (2014). Mother and father-to-infant emotional involvement. In C. M. Pariante, S. Conroy, P. Dazzan, L. Howard, S. Pawlby \& T. Seneviratne (Eds.), Perinatal psychiatry: The legacy of Channi Kumar (pp. 129-143). London, England: Oxford University Press.

Figueiredo, B., \& Conde, A. (2011). Anxiety and depression symptoms in women and men from early pregnancy to 3-months postpartum: Parity differences and effects. Journal of Affective Disorders, 132, 146-157. doi:10.1016/j.jad.2011.02.007

Figueiredo, B., Field, T., Diego, M., Hernandez-Reif, M., Deeds, O., \& Ascenio, A. (2008). Partner relationships during the transition to parenthood. Journal of Reproductive and Infant Psychology, 26, 99-107. doi:10.1080/02646830701873057

Hosmer, D. W., \& Lemeshow, S. (2000). Applied logistic regression (2nd Ed.). New York, NY: Wiley.

Huang, C. C., \& Warner, L. A. (2005). Relationship characteristics and depression among fathers with newborns. Social Service Review, 79, 95-118. doi:10.1086/426719

Kline, R. B. (2005). Principles and practice of structural equation modeling (2nd ed.). New York, NY: Guilford.

Kumar, R., Robson, K. M., \& Smith, A. M. R. (1984). Development of a self-administered questionnaire to measure maternal adjustment and maternal attitudes during pregnancy and after delivery. Journal of Psychosomatic Research, 28, 43-51. doi:10.1016/0022-3999(84)90039-4

Lawrence, E., Rothman, A. D., Cobb, R. J., Rothman, M. T., \& Bradbury, T. N. (2008). Marital satisfaction across the transition to parenthood. Journal of Family Psychology, 22, 41-50. doi:10.1037/0893-3200.22.1.41

Leathers, S. J., \& Kelley, M. A. (2000). Unintended pregnancy and depressive symptoms among first-time mothers and fathers. American Journal of Orthopsychiatry, 70, 523-531. doi: $10.1037 / \mathrm{h} 0087671$

Lovestone, S., \& Kumar, R. (1993). Postnatal psychiatric illness: The impact on partners. British Journal of Psychiatric, 163, 210-216. doi:10.1192/bjp.163.2.210

Marks, M. N., Wieck, A., Checkley, S. A., \& Kumar, R. (1992). Contribution of psychological and social factors to psychotic and non-psychotic relapse after childbirth in women with previous histories of affective disorder. Journal of Affective Disorders, 29, 253-264. doi:10.1016/0165-0327(92)90110-R 
Matthey, S., Barnett, B., Ungerer, J., \& Waters, B. (2000). Paternal and maternal depressed mood during the transition to parenthood. Journal of Affective Disorders, 60, 75-85. doi:10.1016/ S0165-0327(99)00159-7

Mitnick, D. M., Heyman, R. E., \& Smith Slep, A. M. (2009). Changes in relationship satisfaction across the transition to parenthood: A meta-analysis. Journal of Family Psychology, 23, 848-852. doi:10.1037/a0017004

Palkovitz, R., \& Copes, M. (1988). Changes in attitudes, beliefs and expectations associated with the transition to parenthood. Marriage \& Family Review, 12, 183-199. doi:10.1300/ $\mathrm{J} 002 \mathrm{v} 12 \mathrm{n} 03 \_10$
Parfitt, Y., \& Ayers, S. (2014). Transition to parenthood and mental health in first-time parents. Infant Mental Health Journal, 35, 263-273. doi:10.1002/imhj.21443

Spielberger, C. D., Gorsuch, R. L., Lushene, R., Vagg, P. R., \& Jacobs, G. A. (1983). Manual for the State-Trait Anxiety Inventory: STAI (Form Y). Palo Alto: Consulting Psychologists Press.

Teixeira, C., Figueiredo, B., Conde, A., Pacheco, A., \& Costa, R. (2009). Anxiety and depression during pregnancy in women and men. Journal of Affective Disorders, 119, 142-148. doi:10.1016/j.jad.2009.03.005 